\title{
Labor del Coordinador Académico en la gestión del currículo en las organizaciones educativas de secundaria pública
}

\author{
Role of the Academic Coordinator in the curricular \\ management in educational organizations of public \\ high schools
}

\author{
Carolina Mora Valenciano ${ }^{1}$ \\ Ministerio de Educación Pública \\ San José, Costa Rica \\ caroedufi@hotmail.com
}

Recibido 29 setiembre 2011 * Aceptado 05 octubre 2011 * Corregido 29 noviembre 2011

Resumen. Dada la complejidad de los sistemas educativos, en las últimas décadas han surgido nuevos modelos de gestión y organización, basados fundamentalmente en la diversificación y especialización de responsabilidades y funciones y la creación de nuevos puestos de trabajo que han venido a conformar el equipo del director en su papel de gestor de la educación. Es así como surge la figura del Coordinador Académico, su puesto representa una pieza clave en el engranaje de la organización, dada la importancia de los procesos curriculares en la concreción de la misión y visión institucionales. Este proyecto analiza el papel del Coordinador Académico en las organizaciones educativas de secundaria pública, por medio del análisis de datos obtenidos a través de dos cuestionarios aplicados a veintiún directores y veintidós coordinadores académicos de organizaciones educativas de secundaria pública de las regiones educativas de San José y Desamparados. Como resultado de este se define el papel del Coordinador Académico desde la perspectiva del Director y del Coordinador Académico, se identifican las principales funciones del Coordinador en materia de gestión del currículo así como su nivel de cumplimiento y se establece su perfil funcional real. En las conclusiones del estudio se muestra que el coordinador considera que su papel está estrictamente relacionado con el apoyo a la dirección y los docentes en todo lo concerniente a la parte académica. Mientras que desde la perspectiva del Director, el papel del Coordinador Académico está asociado al éxito escolar, al rendimiento académico y al apoyo de los docentes en materia de planeamiento.

Palabras clave: Gestión del currículo, educación, coordinador académico, perfil funcional.

\footnotetext{
1 Licenciada en Ciencias de la Educación con énfasis en Administración Educativa de la Universidad de Costa Rica. Licenciada en Educación Física con énfasis en Docencia de la Universidad Autónoma de Centroamérica. Actualmente labora como docente de educación física del Ministerio de Educación Pública.
}

Número publicado el 20 de diciembre de 2011 URL: http://revistadigital.eae.fcs.ucr.ac.crl 


\begin{abstract}
Through the complexity of educational systems in last decades, new models of management and organization have emerged, based primarily on the diversification and specialization of roles and responsibilities, and new jobs positions that have come to form the principal's team in the role of educational manager. Thus, the Academic Coordinator figure appears; his/her job is a key piece in the organization, because of the importance of curricular processes in order to achieve the institutional mission and vision. This project analyzes the Academic Coordinator role in educational organizations of public high school, through the analysis of the obtained data from two questionnaires applied to twenty-one Principals and twenty-two Academic Coordinators that belong to educational organizations of public high school of Educational Regional Directions of San José and Desamparados. As a result, of Academic Coordinator's role is defined from the perspective of the Principal and Academic Coordinator. The main functions of the Coordinator are defined to manage the curriculum, the level of compliance, and providing real functional profile. The conclusions of the study show that the coordinator believes that his/her role is strictly related to give support to school administration, and teachers in the academic area. Whereas that, from the perspective of the Director, Academic Coordinator's role is associated with school success, academic performance, and support teachers in planning.
\end{abstract}

Key words. Curricular management, education, academic coordinator, functional profile.

\title{
Introducción
}

La educación desempeña un papel de suma relevancia en el desarrollo de un país, pues es a través de ella como se influye decisivamente en las oportunidades y la calidad de vida de los individuos, las familias y las colectividades. Esta representa un conjunto complejo de acciones orientadas a satisfacer las necesidades de las personas. Está sometida a la sociedad y concurre a sus fines, especialmente al desarrollo de sus esfuerzos productivos, atendiendo a la renovación de recursos humanos.

Su misión aspira a permitir, sin excepción, el desarrollo máximo del potencial de las personas haciendo fructificar los talentos de cada uno y su capacidad para realizarse como ser humano y adaptarse a un sistema social.

Actualmente, la educación enfrenta un gran reto, la velocidad con que se produce el conocimiento, la ampliación de oportunidades de acceso y los cambios en las relaciones sociales, interpelan fuertemente a la educación mundial. Es un hecho, que nunca antes en la historia de la humanidad se han operado tantos cambios en un periodo tan corto, y también es evidente que nadie es ajeno ni se puede desarrollar dando la espalda a estos cambios.

Número publicado el 20 de diciembre de 2011 URL: http://revistadigital.eae.fcs.ucr.ac.crl 
Es por ello que los sistemas educativos deben estar en constante evolución, pues su propósito fundamental es el de adaptarse a las necesidades económicas, sociales, culturales y científicas del mundo actual. La transformación educativa parece ser una condición necesaria en la Era del Conocimiento.

Y no es más que en las organizaciones educativas donde se puede concretar todo esta visión, pues ellas "constituyen el medio intencional por excelencia, de las sociedades para alcanzar su visión de sociedad y ser social" (Arroyo, 2009, p.7).

La administración de la educación, por su parte, viene a conformar dentro de las organizaciones educativas, el medio por el cual el sistema educativo pretende garantizar la eficiencia en el funcionamiento y el cumplimiento de esta visión. A través de ella se concilian los intereses y necesidades individuales (factor humano), con las normas y los objetivos institucionales (factor institucional), y las necesidades de demanda social (factor social). La misma parte del objetivo de servir a los propósitos que se definan como filosofía y política de la educación, y para alcanzarlos se provee de recursos humanos, materiales y financieros.

El principal actor de este medio lo constituye el Director, figura en la cual recae la responsabilidad de conseguir el máximo desempeño de la organización educativa, con la eficacia y la eficiencia necesarias para el logro de las metas del sistema educativo. Es él quien guía el potencial humano de los miembros de la organización educativa y sus recursos hacia el logro de la misión y visión organizacional en aras de ofrecer un servicio educativo de calidad.

En este sentido la gestión, entendida como el conjunto de acciones integradas para el logro de los objetivos de la organización, se convierte en el principal eslabón de la cadena de acciones que debe emprender el administrador de la educación para el logro de los objetivos institucionales. La gestión institucional educativa es "una herramienta para crecer en eficacia...además de ser una herramienta para avanzar con mayor precisión hacia los fines educativos que no pueden darse por presupuestos" (Villarreal, 2005, p.1).

Una de las líneas de acción de la gestión institucional, está relacionada con los procesos de trasformación social y el alcance de la excelencia, conocida como la gestión Número publicado el 20 de diciembre de 2011 URL: http://revistadigital.eae.fcs.ucr.ac.crl 
Revista Gestión de la Educación, Vol.1, №2, pp.1-34, ISSN 2215-2288, julio-diciembre, 2011

del currículo. Su función está directamente relacionada con las premisas orientadoras que sustentan la acción pedagógica en el quehacer cotidiano (coherencia), y que se traducen en una propuesta de acción pedagógica (curricular) que impacta directamente la población meta y al contexto (correspondencia). Al respecto, "las organizaciones educativas se consolidan como el instrumento deliberado y el currículum como la acción estratégica de intervención que determina su éxito" (Arroyo, 2009, p.1).

La innovación y disponibilidad de la organización para adaptarse a las nuevas tendencias y requerimientos de la sociedad depende en su mayoría de la capacidad del profesional en administración de la educación para gestionar el currículo.

"Gestar significa pensar y decidir a futuro, construir escenarios, tomar decisiones, planificar en busca de ese camino elegido y todo esto en un contexto determinado" (González y Unfried, 2005, p.2). Para que se lleve a cabo de manera exitosa, el director o directora debe demostrar sensibilidad hacia los problemas educativos y entenderlos, debe tener la capacidad de liderar, pues es una característica imprescindible para el puesto que desempeña.

Toda propuesta de mejora e innovación o desarrollo requiere de directores líderes que apuesten a influir, a inducir a otros a cambiar. Es a través de su liderazgo que se promueven e impulsan los valores educativos, se facilita la aparición de innovaciones y proyectos de transformación.

El liderazgo se ha convertido en una prioridad de las agendas de política educativa, dado su influencia en la eficacia de las organizaciones educativas y las nuevas tendencias que desbancan la administración de tipo burocrático para dar paso a la administración descentralizada donde el director deja de ser el principal responsable de la operación general de la organización que administra, para convertirse en un líder con capacidad de influir en las motivaciones, capacidades y condiciones de trabajo de sus maestros y colaboradores, quienes a su vez moldean la práctica en clase y el aprendizaje de los estudiantes.

En su texto, Bravslavsky, Acosta y Jabif (2004) se refieren a las tres dimensiones del liderazgo dentro de las cuales encontramos: el liderazgo, el estratégico, el comunitario y el pedagógico. Se hace énfasis en este último ya que cuando los profesionales en Número publicado el 20 de diciembre de 2011 URL: http://revistadigital.eae.fcs.ucr.ac.crl 
Revista Gestión de la Educación, Vol.1, N², pp.1-34, ISSN 2215-2288, julio-diciembre, 2011

administración educativa trabajan sobre la dimensión pedagógica del liderazgo, ponen el foco en los procesos de enseñanza-aprendizaje y es ahí donde se logran las verdaderas transformaciones.

Dentro de las características de este tipo de liderazgo están la de fomentar la producción de conocimiento y promover los procesos de reconstrucción de conocimiento a través del pensamiento crítico, así como aumentar la capacidad del colectivo docente para diagnosticar los problemas relevantes del centro educativo e intervenir en acciones concretas y planificadas para mejorar el aprendizaje.

Lo anterior hace pensar que la dirección, tiene la responsabilidad de hacer que su personal se involucre y trabaje en la implementación del proyecto educativo dando sentido a la labor educativa.

La forma en que se hace realidad la implementación de ese proyecto educativo es orientando los procesos pedagógicos, organizacionales y comunitarios a través de líneas de acción, las cuales generen la necesidad de iniciar procesos de mejora comprometiendo a los actores del proceso enseñanza-aprendizaje con la transformación, y partiendo de propuestas de trabajo coordinado que permitan reducir la incertidumbre y los esfuerzos aislados.

Parece que un camino seguro para que la dirección logre la eficacia de su organización es ejerciendo un liderazgo pedagógico y democrático, haciendo partícipes a otras figuras de la organización educativa dentro de su labor, distribuyendo su liderazgo para una mayor eficacia.

"De hecho está surgiendo un conjunto de literatura empírica para fundamentar la idea de que el liderazgo distribuido, cuando se realiza de modo formal o informal, puede mejorar los resultados a nivel educativo". (Moorman, Nusche y Pont, 2009, p.70)

El liderazgo representa comunicación entre los miembros de la organización lo que permite el intercambio de ideas y por tanto el surgimiento de nuevas propuestas. Parece evidente que el recurso humano debe ser considerado como centro de atención en el Número publicado el 20 de diciembre de 2011 URL: http://revistadigital.eae.fcs.ucr.ac.crl 
Revista Gestión de la Educación, Vol.1, N², pp.1-34, ISSN 2215-2288, julio-diciembre, 2011

proceso de gestión directiva, pues es clave para el alcance de niveles óptimos de eficiencia. Una organización que no se fundamente en una distribución de responsabilidades y de cometidos está condenada al fracaso.

Dada la complejidad de los sistemas educativos, en las últimas décadas han surgido nuevos modelos de gestión y organización, basados fundamentalmente en la diversificación y especialización de responsabilidades y funciones y la creación de nuevos puestos de trabajo que han venido a conformar el equipo del director en su papel de gestor de la educación.

En el área de la gestión del currículo, el director, término que en adelante se utilizará para referirnos a ambos géneros para efectos de esta investigación, encuentra su principal apoyo en la Coordinación Académica, quien cumple la función de asesorarlo en la definición de lineamientos y estrategias pedagógicas que contribuyan al mejoramiento de la calidad de los procesos académicos de la institución.

Su puesto representa una pieza clave en el engranaje de la organización, dada la importancia de los procesos curriculares en el cumplimiento de los objetivos de la organización educativa en su calidad de prestadora de servicios educativos que influyen directamente en la visión de ser humano en la sociedad y en la competitividad de un país.

Encontrar la respuesta a las preguntas: ¿cuál es?, ¿cómo definir? y ¿cómo utilizar? la labor de la Coordinación Académica para lograr los aprendizajes esperados y cumplir con las expectativas de mejorar la calidad de la educación se hace una demanda impostergable. Para ello, se establecen los siguientes objetivos:

\section{Objetivo general}

- Analizar la labor de quienes desempeñan el rol de coordinación académica en la gestión del currículo en las organizaciones educativas de secundaria públicas de las direcciones regionales de San José y Desamparados.

Número publicado el 20 de diciembre de 2011 URL: http://revistadigital.eae.fcs.ucr.ac.crl 


\section{Objetivos específicos}

1. Definir el papel de quienes desempeñan el rol de coordinación académica en las organizaciones de educación secundaria pública.

2. Identificar las principales funciones de quienes ejercen la coordinación académica en las organizaciones de educación secundaria pública desde la perspectiva del personal directivo y de quienes llevan a cabo la coordinación académica.

3. Determinar el grado en que se realizan las funciones relacionadas con gestión curricular.

4. Establecer la incidencia de las funciones asignadas a la persona que ejerce la coordinación académica en el éxito de la gestión del currículo.

5. Determinar los factores que tienen mayor incidencia en la labor de coordinación académica en el área de gestión del currículo.

\section{Referencial teórico}

\section{Gestión de la educación}

La gestión es un campo relativamente joven; su evolución data de la década de los años ochenta en América Latina; su conceptualización ha estado ligada a la gerencia de organizaciones, empresas productivas y de servicios. En el campo educativo ha surgido como respuesta a las demandas de la sociedad del conocimiento cada vez más aceleradas.

Al respecto Ogando (2004) explica:

La definición de Administración Educativa ya resulta insuficiente para incluir la coordinación de los procesos escolares y educacionales, por lo que se ha planteado su revisión conceptual para que sea más abarcativo y significante; así

Número publicado el 20 de diciembre de 2011 URL: http://revistadigital.eae.fcs.ucr.ac.crl 
Revista Gestión de la Educación, Vol.1, N², pp.1-34, ISSN 2215-2288, julio-diciembre, 2011

hemos visto en los países iberoamericanos el surgimiento de un campo emergente: el de la gestión de los procesos educativos. (p.2)

Gestionar representa gobernar, pero más allá de este concepto, se refiere a una forma de comprender y conducir una organización al cumplimiento de sus metas a través de un conjunto de acciones que pretenden la máxima eficacia de un sistema por medio de la integración de todas las partes. Significa pensar y decidir a futuro, construir escenarios, tomar decisiones, planificar en busca de ese camino elegido y todo esto en un contexto determinado.

Todas las organizaciones necesitan gestar procesos para lograr su sostenibilidad, su credibilidad, su legitimidad en el contexto en el cual y para el cual fueron creadas.

En el ámbito educativo la gestión busca aplicar principios que han estado presentes en la teoría de la administración; sin embargo, en su concepción encontramos el factor humano como eje principal y una serie de disciplinas que la enriquecen desde la psicología y la sociología, hasta la filosofía y las ciencias sociales.

La gestión está constituida por espacios definidos por el director donde se formulan estrategias dirigidas a organizar los conocimientos del recurso humano y desarrollar sus posibilidades al máximo en pro de la visión institucional y con el fin último de ofrecer un servicio educativo de calidad. (Arroyo, 2009, p.9)

Por otra parte, la gestión se define como "la importancia del compromiso de las personas con la institución, y la responsabilidad que tienen los profesores y administradores en avanzar hacia la misión institucional a través de esfuerzos personales y como integrantes de equipos de trabajo" (Lepeley, 2003, p.6).

Las acciones que conlleva la gestión de las organizaciones educativas implican espacios en los que el profesional en administración de la educación "concibe, prepara, desarrolla y fortalece de forma particular y grupal el potencial de su personal docente y administrativo para que actúen sobre los recursos organizacionales y pueda así 
Revista Gestión de la Educación, Vol.1, N², pp.1-34, ISSN 2215-2288, julio-diciembre, 2011

alcanzarse la visión y misión definidas formalmente para la organización" (Arroyo, 2009, p.12).

En otras palabras, la gestión ha sido concebida como un proceso orientado al fortalecimiento de proyectos educativos en el marco de las políticas públicas, enriqueciendo los procesos pedagógicos para responder a las necesidades educativas de una nación.

\section{Referentes de la gestión educativa}

El propósito de la gestión educativa debe ser promotor de mejoramiento; es por ello que se ha tomado como base la información expuesta en la guía de mejoramiento institucional elaborada por el Ministerio de Educación Nacional de Colombia (MEN), en el año 2009, en el marco de autoevaluación y mejoramiento institucional, para conocer los referentes de la gestión educativa. A continuación un resumen de estos:

- La gestión administrativa y financiera: tiene a su cargo el diseño, ejecución y evaluación de acciones que buscan dar soporte a la misión institucional mediante el uso efectivo de los recursos.

- La gestión académica: a través de este tipo de gestión se actualizan permanentemente los planes de estudio y las estrategias de articulación de grados, niveles y áreas, así como las metodologías de enseñanza, el desarrollo de proyectos transversales y el trabajo de aula.

- La gestión de la comunidad: se refiere a las acciones que fortalecen la identidad de la organización educativa y le brindan un sentido de pertinencia. El ámbito en el que se desarrollan estas acciones vincula a todos los actores de la comunidad y a la organización institucional con su entorno.

Número publicado el 20 de diciembre de 2011 URL: http://revistadigital.eae.fcs.ucr.ac.crl 
Revista Gestión de la Educación, Vol.1, N², pp.1-34, ISSN 2215-2288, julio-diciembre, 2011

\section{Componentes de la gestión}

Para lograr sus objetivos, el personal directivo debe cumplir con ciertos requisitos como son: la reflexión, la toma de decisiones y el liderazgo eficaz. Al respecto, el Ministerio de Educación de Chile (MINEDUC), en el año 2005, indica que "la gestión tiene tres componentes: El pensamiento sistemático y estratégico, el liderazgo pedagógico y el aprendizaje organizacional" (Fonseca, 2006, p.32).

- El pensamiento estratégico: consiste en saber qué debe suceder, a través de la toma de decisiones, la gestión educativa construye acciones y comunicaciones necesarias para concretar una visión de futuro y los objetivos para el alcance de las metas.

- El liderazgo pedagógico: se concreta cuando el administrador inspira y motiva a su equipo de trabajo para que conciban el camino hacia un producto de calidad como una meta común que se alcanza con la articulación de esfuerzos de todas las partes.

- Aprendizaje organizacional: entendido como un proceso de generación y transferencia que puede verse facilitado o entorpecido por el contexto sociohistórico y cultural en el cual estos aprendizajes tienen lugar. Este debe insertarse en una cultura que facilite el aprendizaje y el mejoramiento continuo que debe verse reflejado en el proceso de elaboración e implementación de planes de mejoramiento educativo.

Número publicado el 20 de diciembre de 2011 URL: http://revistadigital.eae.fcs.ucr.ac.crl 


\section{Actores de la gestión educativa}

En el espacio concreto donde se plasman las políticas educativas concebido como la organización educativa, el encargado de la gestión es la persona que ejerce la dirección, quien tiene la tarea de dirigir todo el proceso desde dos ámbitos de trabajo: el administrativo y el académico, con la articulación de las competencias de todo su personal.

Dentro de sus cometidos debe estar la orientación del talento individual y grupal, la promoción de acciones cooperativas, el fortalecimiento del trabajo en equipo, así como la estimulación del desempeño laboral y el compromiso social hacia un servicio de calidad.

\section{Ámbitos de acción}

En el marco de la gestión de calidad, MINEDUC (2005) propone cuatro ámbitos de acción que se detallan a continuación:

- Liderazgo: comprende los procedimientos desarrollados por el equipo directivo para orientar, planificar, articular y evaluar los procesos institucionales.

- Gestión del recurso humano: envuelve la totalidad de las prácticas realizadas en el establecimiento educacional para asegurar tanto el desarrollo de docentes y asistentes de educación como la organización y optimización de los recursos en función del logro de los objetivos y metas institucionales.

- Gestión de la convivencia o clima organizacional: en esta área convergen las acciones que se realizan en el establecimiento educacional para considerar las diferencias individuales de los actores de la comunidad educativa y promover la convivencia de estos favoreciendo un ambiente propicio para el aprendizaje.

Número publicado el 20 de diciembre de 2011 URL: http://revistadigital.eae.fcs.ucr.ac.crl 
Revista Gestión de la Educación, Vol.1, №2, pp.1-34, ISSN 2215-2288, julio-diciembre, 2011

- Gestión curricular: involucra a todas las prácticas realizadas en el establecimiento educacional para asegurar desde la sustentabilidad del diseño e implementación de una propuesta curricular hasta la evaluación del mismo en coherencia con el Proyecto Educativo Institucional. Al ser esté ámbito de acción eje principal para el logro de la visión y misión institucionales, en adelante se profundiza en esta área.

\section{Gestión del currículo}

Dentro del marco de la globalización en los últimos años se han presentado cambios sustanciales en el contexto social en el cual nos situamos, que afectan desde la concepción de ser humano, la percepción y la convivencia con el medio ambiente hasta las formas de vivir y los papeles de los individuos en la sociedad. Estas demandas llevan a una nueva consideración del concepto de calidad educativa y a una preocupación permanente por la mejora de los procesos y de los resultados De hecho a menudo se habla de una nueva realidad a la que hay que adaptarse personal e institucionalmente, si no queremos marginarnos del progreso.

La realidad educativa no ha sido ajena a estos procesos de cambio. Esta es dinámica, como lo es la realidad sociocultural en la cual se enmarca y este dinamismo ha explicado la necesidad de actualizar el conjunto de decisiones que acompañan a la ordenación de nuestra intervención educativa con el fin de perfeccionar los servicios que se prestan.

El currículo se ha convertido en el punto crítico de la política educativa en el mundo, por cuanto, de acuerdo con la dinámica en que interactúen los sujetos, procesos y elementos que la conforman así van a ser los alcances en cuanto al logro de capacidades y valores de la persona humana y la satisfacción de la demanda educativa de la sociedad.

Las instituciones educativas deben ser un modelo que promueva una gestión, acorde con los cambios permanentes que enfrenta la sociedad actual, es decir, una institución que está en constante aprendizaje y en un proceso permanente de mejora, adaptándose a las necesidades de la sociedad.

Número publicado el 20 de diciembre de 2011 URL: http://revistadigital.eae.fcs.ucr.ac.crl 
Revista Gestión de la Educación, Vol.1, N², pp.1-34, ISSN 2215-2288, julio-diciembre, 2011

Pero ninguna transformación puede realizarse independientemente de la realidad social, cultural y económica que posibilita y condiciona la existencia de las organizaciones educativas y de la misma educación. Esta debe vincularse a esas realidades, atender sus demandas y paralelamente, las exigencias que plantean la vida institucional donde se desarrolla y los nuevos enfoques de las ciencias de la educación.

Se habla de efectividad en la gestión escolar cuando el centro educativo logra que sus estudiantes aprendan lo que deben aprender, en el tiempo que lo deben hacer y utilizando adecuadamente los recursos disponibles. El Ministerio de Educación de El Salvador (MINED), en el año 2008, menciona al respecto, que el propósito de la educación es lograr que se tenga la población ciudadana para forjar el país que se quiere.

Así surge el término de gestión del currículo, como un elemento preponderante en los procesos de transformación de las organizaciones educativas que viene a garantizar la pertinencia y calidad de las propuestas educativas respondiendo a los desafíos, compromisos y objetivos que se han planteado en el ámbito estratégico.

"La capacidad de organizar y poner en marcha el proyecto pedagógico de la institución a partir de la definición de qué se debe enseñar y qué deben aprender los estudiantes" (Mora, 2010, p.1).

Se dice que toda institución que busque mejorar sus procesos internos, en vías de entregar una educación de calidad a sus alumnos, debe considerar el factor gestión curricular como columna vertebral en el camino hacia la mejora continua. Esto implica mirar con atención aquellas prácticas exitosas, de manera de incorporarlas en forma sistemática en la cultura institucional.

Sin embargo, no se debe pasar por alto el desarrollo de una cultura profesional abierta, participativa, reflexiva, autoevaluativa y autocrítica, todo es un paso indispensable para obtener la legitimidad y el poder educador que las organizaciones educativas necesitan.

Número publicado el 20 de diciembre de 2011 URL: http://revistadigital.eae.fcs.ucr.ac.crl 


\section{Dimensiones de la gestión del currículo}

El Gobierno de Chile, a través del MINEDUC (2005) ha elaborado un Modelo de gestión de calidad, donde divide la gestión del currículo en cuatro dimensiones que le dan viabilidad:

- Organización curricular: prácticas que aseguran que la propuesta curricular diseñada sea coherente con el Proyecto Educativo Institucional y articulada con el Marco Curricular, en el contexto de las necesidades formativas y educativas de los estudiantes.

- Preparación de la enseñanza: está constituida por las acciones de la organización educativa que aseguran la organización, análisis y evaluación del proceso de enseñanza - aprendizaje para la implementación del currículo en el aula.

- Acción docente en el aula: son las prácticas que dan paso a que la implementación curricular se concrete eficazmente en el aula a través del proceso enseñanza - aprendizaje.

- Evaluación de la implementación curricular: a través de esta dimensión se logra determinar el grado de desarrollo e impacto que tiene la implementación del diseño curricular.

La gestión curricular es un tema que repercute directamente en la calidad de la educación. Saber implementar en forma eficiente el currículo nacional a nivel de unidad educativa, depende de las competencias y habilidades (estándares educacionales) que cada integrante de la unidad educativa posee, para después llevarla a nivel de aula, es la gran barrera que debe romper nuestro sistema educativo para tener éxito en el proceso de enseñanza aprendizaje.

Número publicado el 20 de diciembre de 2011 URL: http://revistadigital.eae.fcs.ucr.ac.crl 
Revista Gestión de la Educación, Vol.1, N², pp.1-34, ISSN 2215-2288, julio-diciembre, 2011

En el enfoque y estructuración curricular deben participar todos los agentes educativos; sin embargo, y dependiendo del rol que estos desempeñen dentro de la institución educativa, cada uno tiene unas funciones relacionadas con la gestión curricular.

\section{Coordinador académico}

Una de las debilidades de los sistemas educativos en América Latina radica en no distinguir claramente los procesos de la organización escolar y el papel que juega cada uno de los profesionales que laboran en ella. Es decir, "en la práctica cotidiana, muchas veces se confunden o no hay claridad de las funciones que corresponde desarrollar y, como consecuencia de ello, se diluyen las responsabilidades" (Fundación Chile, 2006, p.4).

Después de haber estudiado la gestión del currículo, es conveniente centrar la atención en los actores de este proceso, dado que no se puede hablar del mismo, sin tomar en cuenta el factor humano como eje potenciador de su existencia.

Para encarar con eficacia la gestión curricular, garantizando a todos los actores del sistema educativo procesos transparentes de selección, evaluación y perfeccionamiento, así como formación de equipos docentes competentes y capaces de entregar una educación de calidad a los estudiantes, hay que tomar en cuenta las competencias de quienes tienen principal injerencia en estos procesos.

Los ministros de educación de los países de América Latina y el Caribe aprobaron un conjunto de recomendaciones que evidencian que "la profesionalización de la acción educativa es el concepto central que debe caracterizar las actividades de esta nueva etapa del desarrollo educativo" (Bar, 1999, Capítulo 3, párr. 11).

Dado lo anterior, se considera importante la utilización de los Perfiles de Competencias como una herramienta extraordinaria de profesionalización con el objetivo de examinar las prácticas de la institución, motivar la autoevaluación e impulsar planes de

Número publicado el 20 de diciembre de 2011 URL: http://revistadigital.eae.fcs.ucr.ac.crl 
Revista Gestión de la Educación, Vol.1, N², pp.1-34, ISSN 2215-2288, julio-diciembre, 2011

desarrollo individual y organizacional con grandes posibilidades de éxito en los sistemas educativos.

Una figura clave que recientemente surge en la tarea de gestionar el currículo en las organizaciones educativas de secundaria es el coordinador académico, figura en quien recae la responsabilidad de asesorar al director en lo relativo a la programación, organización, supervisión y evaluación de las actividades curriculares que se desarrollan en las organizaciones educativas.

\section{Papel del coordinador académico}

El coordinador académico es directamente responsable de impulsar el trabajo de profesores, profesoras y estudiantes. Es su responsabilidad poner en marcha los planes y programas de estudio diseñados para cada uno de los niveles; y, dar seguimiento a los profesores y profesoras en los aspectos técnicos del trabajo, asesorarlos en sus dificultades y apoyarlos en todo momento, además de mantener un programa de formación del profesorado que promueva las buenas prácticas velando por la calidad de la educación.

Para lograr lo anterior, el trabajo del coordinador debe estar fundamentado en cuatro principios generales: reflexión, planeación, investigación y participación.

Mediante la reflexión, se busca que la comunidad docente asuma una conciencia crítica acerca del quehacer pedagógico y se vea motivado a plantear nuevas propuestas que posibiliten la constante superación de los procesos de enseñanza y aprendizaje.

Con la planeación, se pretende garantizar la estabilidad de estos mismos procesos, asegurando los recursos didácticos y la formación de los docentes y estableciendo mecanismos de verificación y validación que permitan asegurar la calidad del servicio que se ofrece a la comunidad educativa.

La investigación es entendida como la oportunidad que tiene la institución de conocer los distintos avances en el campo educativo nacional o internacional, con el fin de

Número publicado el 20 de diciembre de 2011 URL: http://revistadigital.eae.fcs.ucr.ac.crl 
Revista Gestión de la Educación, Vol.1, º2, pp.1-34, ISSN 2215-2288, julio-diciembre, 2011

retroalimentar los procesos internos y poder rediseñar un currículo ajustado a las necesidades de las nuevas generaciones de estudiantes.

Finalmente, la participación se plantea como la posibilidad que todos los miembros de nuestra comunidad educativa (estudiantes, padre de familia, docentes, personal de apoyo, administrativo y de servicios) tienen de hacer sus aportes para que los procesos de enseñanza y aprendizaje sean cada vez más eficaces, de tal modo que realmente sirvan en la consolidación de la misión y visión institucional.

La forma en que el coordinador académico incide en la gestión curricular es cumpliendo con una serie de funciones que se sustentan en el planeamiento, organización, dirección y control de todas las actividades relacionadas con la gestión curricular.

No se puede dejar de lado la importancia que tienen las características personales y la experiencia del coordinador académico en el ámbito educativo, pues este debe ser una persona proactiva, que presente una serie de condiciones y cualidades necesarias para su puesto; con capacidad de percibir las necesidades de su entorno y generar líneas de acción que le permitan solucionar problemas y crear espacios para la comunicación, dado que es el principal encargado de difundir y asegurar la participación de la comunidad educativa y de su entorno en los procesos educativos.

\section{Ámbito costarricense}

Dentro del estatuto de Servicio Civil costarricense no existe la descripción del puesto de coordinación académica; sin embargo, el Ministerio de Educación Pública, en el año 2008, por medio de una directriz suscrita por la Viceministra Académica (2006-2010), Alejandrina Mata Segreda, publicó un documento titulado "Naturaleza del Trabajo de Coordinación Académica", el cual incluye las áreas:

- Funcional: Desempeño de las tareas específicas del rol coordinación académica.

Número publicado el 20 de diciembre de 2011 URL: http://revistadigital.eae.fcs.ucr.ac.crl 
Revista Gestión de la Educación, Vol.1, N², pp.1-34, ISSN 2215-2288, julio-diciembre, 2011

- Conductual: Características personales, actitudes, valores, intereses y motivaciones en el ejercicio de la labor desempeñada.

- Profesional: Requerimientos para ejercer el puesto de coordinación académica dentro de la organización educativa en el área del conocimiento y la experiencia.

Para efectos de este proyecto de investigación, se trabajó con el análisis de la labor en el área funcional utilizando como base las tareas establecidas en la directriz emanada al respecto (MEP, 2008), las mismas, fueron divididas en tareas de: planeación, organización, dirección y control, según su naturaleza. Con el fin de determinar el nivel de cumplimiento de las funciones por área y establecer las funciones más relevantes en el área de gestión del currículo.

A continuación, se presentan algunos rasgos establecidos para el perfil general, en relación con el área funcional de la coordinación académica (MEP, 2008):

\section{- $\quad$ El perfil funcional}

- $\quad$ Servir de enlace entre el personal académico y la dirección.

- $\quad$ Asesorar al personal docente en aspectos de desarrollo curricular.

- $\quad$ Colaborar en la divulgación de políticas y planes del MEP.

- $\quad$ Confeccionar instrumentos de investigación y control.

- $\quad$ Representar a la dirección en el Comité de Trabajo Comunal.

- $\quad$ Realizar estudios de rendimiento académico.

- $\quad$ Participar en reuniones referentes a su labor.

- $\quad$ Coordinar con los Departamentos Especializados estudios y procesos de recuperación con fines de mejorar el rendimiento académico.

- $\quad$ Colaborar en la organización de las semanas de evaluación y otras actividades institucionales.

- $\quad$ Organizar el calendario administrativo con la dirección.

- $\quad$ Apoyar al Departamento de Orientación y de Apoyo en proyectos Estudiantiles y adecuaciones curriculares.

Número publicado el 20 de diciembre de 2011 URL: http://revistadigital.eae.fcs.ucr.ac.crl 
Revista Gestión de la Educación, Vol.1, N², pp.1-34, ISSN 2215-2288, julio-diciembre, 2011

- Coordinar, planificar y dar seguimiento a programas de desarrollo curricular.

- $\quad$ Otras que se le designen.

El perfil pretende ser una guía tanto para la coordinación académica, para priorizar las funciones de acuerdo con las necesidades de la organización educativa, como para la dirección responsable de encaminar al personal al cumplimiento de los propósitos organizacionales.

\section{Metodología}

En esta investigación, calificada como descriptiva (Hernández, Fernández y Baptista, 2010), participan los directores y directoras, conjuntamente con los coordinadores académicos de las organizaciones de secundaria de cuatro direcciones regionales de San José, a saber: San José Central, San José Sur-Oeste, San José Norte y Desamparados. Los colegios fueron escogidos aleatoriamente y los directores y coordinadores académicos que participan son los que mostraron anuencia e interés por colaborar con este estudio completando el cuestionario y la escala.

Para lograr la consecución de los objetivos de este estudio, se establecen las siguientes categorías de análisis, con el fin de determinar su incidencia en la gestión curricular e identificar el perfil que caracteriza al profesional docente que ejerza la coordinación académica en las organizaciones educativas.

Número publicado el 20 de diciembre de 2011 URL: http://revistadigital.eae.fcs.ucr.ac.crl 
Revista Gestión de la Educación, Vol.1, №2, pp.1-34, ISSN 2215-2288, julio-diciembre, 2011

Tabla 1

Operacionalización de los objetivos de la investigación

\begin{tabular}{|c|c|c|c|c|}
\hline $\begin{array}{l}\text { Objetivos } \\
\text { Específicos }\end{array}$ & $\begin{array}{l}\text { Unidades De } \\
\text { Análisis }\end{array}$ & Definición Conceptual & $\begin{array}{l}\text { Definición } \\
\text { Instrumental }\end{array}$ & $\begin{array}{l}\text { Definición } \\
\text { Operacional }\end{array}$ \\
\hline $\begin{array}{l}\text { Definir el papel del } \\
\text { Coordinador } \\
\text { Académico en las } \\
\text { Organizaciones de } \\
\text { Educación } \\
\text { Secundaria } \\
\text { Pública. }\end{array}$ & $\begin{array}{l}\text { Papel del } \\
\text { Coordinador } \\
\text { Académico }\end{array}$ & 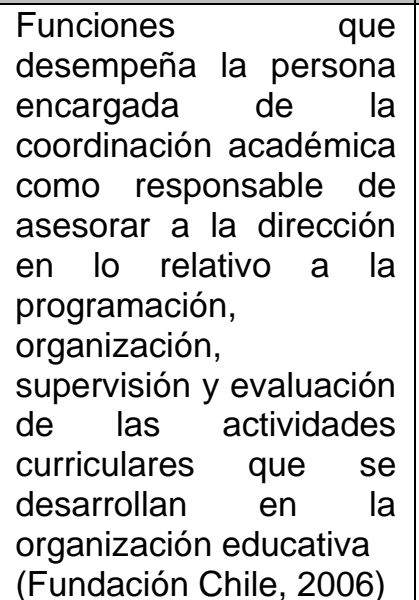 & $\begin{array}{l}\text { Se mide a } \\
\text { través del } \\
\text { cuestionario } \\
\text { en la pregunta } \\
\text { abierta } N^{\circ} 11 \\
\text { en la sección } \\
\text { de Datos } \\
\text { relacionados } \\
\text { con la labor } \\
\text { del } \\
\text { Coordinador } \\
\text { Académico. }\end{array}$ & $\begin{array}{l}\text { Se analizan las } \\
\text { respuestas dadas } \\
\text { por los Directores } \\
\text { y Coordinadores } \\
\text { Académicos } \\
\text { consultados para } \\
\text { definir el papel del } \\
\text { coordinador } \\
\text { académico. }\end{array}$ \\
\hline $\begin{array}{ll}\text { Identificar } & \text { las } \\
\text { principales } & \\
\text { funciones } & \text { del } \\
\text { Coordinador } & \\
\text { Académico en } & \text { las } \\
\text { Organizaciones } & \end{array}$ & $\begin{array}{c}\text { Principales } \\
\text { funciones del } \\
\text { Coordinador } \\
\text { Académico en } \\
\text { las } \\
\text { organizaciones } \\
\text { de secundaria. } \\
\end{array}$ & $\begin{array}{l}\text { Se refiere a las } \\
\text { funciones } \\
\text { administrativas y de } \\
\text { gestión del currículo que } \\
\text { los coordinadores y } \\
\text { coordinadoras así como } \\
\text { personal directivo, }\end{array}$ & 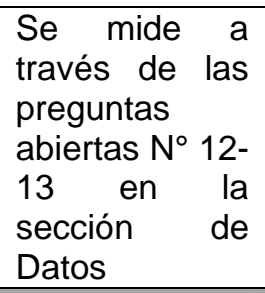 & $\begin{array}{l}\text { Las funciones se } \\
\text { determinan } \\
\text { mediante las } \\
\text { respuestas } \\
\text { brindadas por los } \\
\text { Directores y } \\
\text { Coordinadores } \\
\end{array}$ \\
\hline $\begin{array}{l}\text { Objetivos } \\
\text { Específicos }\end{array}$ & $\begin{array}{l}\text { Unidades De } \\
\text { Análisis }\end{array}$ & Definición Conceptual & $\begin{array}{l}\text { Definición } \\
\text { Instrumental }\end{array}$ & $\begin{array}{l}\text { Definición } \\
\text { Operacional }\end{array}$ \\
\hline $\begin{array}{l}\text { de Educación } \\
\text { Secundaria } \\
\text { Pública. }\end{array}$ & & $\begin{array}{l}\text { consideran inherentes al } \\
\text { rol de coordinación } \\
\text { académica. } \\
(\mathrm{MEP}, 2008)\end{array}$ & $\begin{array}{l}\text { relacionados } \\
\text { con la labor } \\
\text { del } \\
\text { Coordinador } \\
\text { Académico. } \\
\end{array}$ & $\begin{array}{l}\text { Académicos } \\
\text { consultados. }\end{array}$ \\
\hline $\begin{array}{ll}\text { Determinar } & \text { el } \\
\text { grado en que se } \\
\text { realizan } & \text { las } \\
\text { funciones } & \\
\text { relacionadas con } \\
\text { gestión curricular. }\end{array}$ & $\begin{array}{l}\text { Cumplimiento } \\
\text { de las funciones } \\
\text { relacionadas } \\
\text { con la gestión } \\
\text { curricular }\end{array}$ & $\begin{array}{l}\text { Nivel de cumplimiento } \\
\text { de las funciones de } \\
\text { planeación, } \\
\text { organización, } \\
\text { seguimiento y control } \\
\text { relacionadas con la } \\
\text { gestión del currículo en } \\
\text { las organizaciones } \\
\text { educativas r se } \\
\text { secundaria públicas, } \\
\text { MEP (2008) }\end{array}$ & $\begin{array}{l}\text { Se aplica un } \\
\text { cuestionario } \\
\text { organizado en } \\
\text { una tabla con } \\
\text { todas las } \\
\text { funciones } \\
\text { dadas por el } \\
\text { M.E.P } \\
\text { divididas en } \\
\text { funciones de } \\
\text { planeación, } \\
\text { organización, } \\
\text { dirección y } \\
\text { control. }\end{array}$ & $\begin{array}{lr}\text { A través de las } \\
\text { elecciones de los } \\
\text { Directores r y } \\
\text { Coordinadores } \\
\text { entre niveles: } \\
\text { Alto-Medio } \quad \text { o } \\
\text { Bajo, re } \\
\text { determina el nivel } \\
\text { en que re } \\
\text { cumplen r las } \\
\text { funciones } \\
\text { relacionadas con } \\
\text { la gestión del } \\
\text { currículo. }\end{array}$ \\
\hline $\begin{array}{lr}\text { Establecer } & \text { la } \\
\text { incidencia de las }\end{array}$ & $\begin{array}{l}\text { Funciones que } \\
\text { determinan el }\end{array}$ & $\begin{array}{l}\text { Conjunto sistemático y } \\
\text { planificado de prácticas }\end{array}$ & $\begin{array}{l}\text { Se mide } a \\
\text { través de las }\end{array}$ & $\begin{array}{l}\text { Se analizan las } \\
\text { respuestas dadas }\end{array}$ \\
\hline
\end{tabular}

Número publicado el 20 de diciembre de 2011 URL: http://revistadigital.eae.fcs.ucr.ac.crl 
Revista Gestión de la Educación, Vol.1, º2, pp.1-34, ISSN 2215-2288, julio-diciembre, 2011

\begin{tabular}{|c|c|c|c|c|}
\hline $\begin{array}{l}\text { funciones } \\
\text { asignadas al } \\
\text { Coordinador } \\
\text { Académico en el } \\
\text { éxito de la Gestión } \\
\text { del Currículo. }\end{array}$ & $\begin{array}{c}\text { éxito en la } \\
\text { gestión. }\end{array}$ & $\begin{array}{l}\text { que aseguran la puesta } \\
\text { en marcha del proyecto } \\
\text { curricular (Unicef, 2004). }\end{array}$ & $\begin{array}{l}\text { preguntas } \\
\text { abiertas } N^{\circ} 14- \\
15\end{array}$ & $\begin{array}{lr}\text { por } & \text { los } \\
\text { consultados para } \\
\text { determinar si } \\
\text { cuentan con un } \\
\text { perfil de funciones } \\
\text { y si este asegura } \\
\text { el éxito en la } \\
\text { gestión } \\
\text { currículo } \\
\text { realizan. }\end{array}$ \\
\hline $\begin{array}{lr}\text { Determinar } & \text { los } \\
\text { factores de mayor } \\
\text { incidencia en la } \\
\text { labor } \\
\text { Coordinador } \\
\text { Académico. }\end{array}$ & $\begin{array}{c}\text { Factores de } \\
\text { incidencia en la } \\
\text { labor del } \\
\text { Coordinador } \\
\text { Académico }\end{array}$ & $\begin{array}{l}\text { Se refiere a elementos } \\
\text { materiales u } \\
\text { organizacionales que } \\
\text { afectan directamente la } \\
\text { labor de quienes tienen } \\
\text { el rol de coordinación } \\
\text { académica. }\end{array}$ & $\begin{array}{l}\text { Se mide } r \\
\text { través de las } \\
\text { pregunta } N^{\circ} 9 \\
\text { de opción } \\
\text { única y la } \\
\mathrm{N}^{\circ} 10 \quad-16 \text { de } \\
\text { opción } \\
\text { múltiple. }\end{array}$ & $\begin{array}{l}\text { Se determina } \\
\text { porcentualmente } \\
\text { la importancia } \\
\text { que los } \\
\text { consultados } \\
\text { atribuyen a cada } \\
\text { uno de los } \\
\text { factores. }\end{array}$ \\
\hline
\end{tabular}

Fuente: Elaboración propia a partir de la investigación realizada.

\section{Instrumento y recolección de datos}

Con el propósito de obtener los datos y cumplir con los objetivos propuestos se diseñó un cuestionario validado según los criterios de Ary, Jacobs y Razavieh (1989), compuesto por 16 ítems en la primera parte, subdividida en dos secciones: la primera que corresponde a preguntas relacionadas con datos personales tales como: años de servicio, especialidad docente, años de laborar en la institución. La segunda, conformada por preguntas abiertas y cerradas donde se solicita a los participantes que se refirieran a la figura de Coordinador Académico y las funciones tanto académicas como administrativas inherentes a su cargo (ver Anexo 1).

La segunda parte del cuestionario está conformada por una tabla compuesta por las funciones de planeamiento, organización, control y dirección y a mano derecha las opciones del nivel (alto, medio, bajo, no responde) en que se realizan las funciones.

Los datos fueron recolectados por medio de los instrumentos descritos, aplicados por la investigadora del proyecto en las organizaciones educativas que accedieron a brindar la información.

Número publicado el 20 de diciembre de 2011 URL: http://revistadigital.eae.fcs.ucr.ac.crl 


\section{Análisis de datos}

\section{Información general}

En este apartado se encuentra que la mayoría $(68,2 \%)$ de Coordinadores Académicos consultados son docentes con más de quince años de laborar en educación, lo cual permite afirmar que en una buena parte de los docentes nombrados como coordinadores académicos son personas con amplia trayectoria en el sector educación. Los datos relacionados con la especialidad docente indican que un $77,27 \%$ de los consultados se desempeñan como docentes de materias básicas, lo anterior indica que los directores prefieren para el puesto de Coordinador Académico a aquellos docentes cuya especialidad es una materia básica.

\section{Datos relacionados con las funciones de coordinación académica}

\section{¿Cuenta el docente que lleva a cabo la coordinación académica con un perfil de funciones definido?}

Al preguntar a los coordinadores académicos si cuentan con un perfil de funciones que guíe su labor diaria en la organización educativa los resultados evidencian que la mayoría $(68,18 \%)$ de los coordinadores académicos sí cuenta con algún tipo de perfil, ya sea el definido por la dirección o el que brinda el Ministerio de Educación Pública. Los coordinadores que se encuentran dentro de este porcentaje aseguran que: "el perfil es establecido según necesidades", "desde inicio de año se coordina con la dirección para establecer las funciones a desarrollar", "aunque están definidas las funciones la persona que cumpla este cargo debe cumplir con ciertas características personales tales como: capacidad de organización, liderazgo y buenas relaciones personales para que sea un enlace y un apoyo a la gestión administrativa", "si están definidas pero en realidad se ayuda a la dirección en muchas otras funciones a nivel administrativo", "si hay un perfil 
Revista Gestión de la Educación, Vol.1, º2, pp.1-34, ISSN 2215-2288, julio-diciembre, 2011

basado en lo que ofrece el MEP; sin embargo no hay claridad en cuanto a las funciones a desarrollar".

El 31,82\% de coordinadores afirma no contar con un perfil de funciones definido. Estos apoyan su respuesta con las siguientes afirmaciones: "el perfil que manda el MEP como tal es muy deficiente", "no hay un manual designado solo depende del grado académico y de la designación del director", "es empírico y lo establece la dirección regente", "el perfil brindado por el MEP no está acorde con las necesidades de la organización educativa y no abarca lo suficiente", "no existe un documento que defina claramente el rol que debe cumplir un coordinador académico".

A pesar de que un porcentaje elevado de coordinadores cuenta con un perfil de funciones definido, el mismo es muy limitado, en algunos casos es definido por la dirección y en otros se basa únicamente en lo estipulado por el MEP. Algunos coordinadores no tienen claro cuáles son sus funciones y a los mismos se les recargan labores administrativas. Hay quienes ni siquiera conocen que existe una directriz emanada por el MEP indicando las funciones del Coordinador Académico.

A pesar de que la mayoría $(87,71 \%)$ de los consultados indica contar con un perfil de funciones, dentro de las respuestas de los consultados encontramos argumentos que permiten deducir que en algunos casos no existe una idea clara sobre el perfil de funciones y su trascendencia, y el perfil utilizado en la mayoría de los casos es el designado por el MEP sin ninguna priorización de acuerdo con las necesidades de la institución. Inclusive encontramos que algunos directores señalan utilizar el manual descriptivo de puestos siendo esta respuesta equivocada debido a que todavía no existe la descripción del puesto del Coordinador Académico.

Se debe recordar que la profesionalización en el ámbito de la educación se ha convertido en una herramienta de desarrollo necesaria para responder a las demandas de la educación actual y el puesto del coordinador representa una pieza clave en el engranaje de la organización de ahí la importancia de tener claridad en cuanto al rol que juega el coordinador y las funciones que debe cumplir para alcanzar el propósito para el que fue creado su puesto.

Número publicado el 20 de diciembre de 2011 URL: http://revistadigital.eae.fcs.ucr.ac.crl 
Revista Gestión de la Educación, Vol.1, N², pp.1-34, ISSN 2215-2288, julio-diciembre, 2011

¿Qué factores tienen mayor incidencia en la labor de quienes ejercen la coordinación académica?

En relación con los factores que inciden en la labor de la coordinación académica en el área de gestión de currículo. Los coordinadores tenían la oportunidad de escoger varias o todas las opciones que se presentan a continuación: número de lecciones asignadas, liderazgo ejercido, ambiente laboral, recurso material, distribución de lecciones, otros.

De la información recopilada se obtiene que el material brindado (72,73\%) para realizar las labores relacionadas con la gestión del currículo, así como el ambiente laboral $(72,73 \%)$ y el liderazgo ejercido por la dirección $(72,73 \%)$, son los factores que los coordinadores académicos consideran tienen más incidencia en su labor.

De la información brindada por la dirección, el porcentaje más alto lo ocupa el liderazgo que ejerce, con un 95,24\%.

\section{¿Inciden las funciones asignadas a la coordinación académica sobre el éxito en la gestión del currículo?}

Se consultó acerca de la incidencia de las funciones asignadas en el perfil sobre el éxito en la gestión del currículo y como resultado del análisis de datos se encuentra que existen opiniones divididas; así un 50\% de los coordinadores opinan positivamente acerca de las funciones asignadas mientras el otro $50 \%$ considera que las funciones asignadas no aseguran el éxito en la gestión curricular. Aquellos coordinadores opinan que las funciones que se les asignan sí aseguran el éxito sobre la gestión del currículo, y complementan su respuesta con las siguientes afirmaciones: "Sí, pero no en un 100\% ya que se da un recargo de funciones y una limitación al no existir un instructivo del MEP, además el tener que dar clases limita el rango de acción". "En teoría sí, pero se necesitan capacitaciones". "El puesto del Coordinador Académico es un apoyo esencial para la labor docente, pues permite dar inducción y seguimiento al personal y trabajar más en los Número publicado el 20 de diciembre de 2011 URL: http://revistadigital.eae.fcs.ucr.ac.crl 
Revista Gestión de la Educación, Vol.1, №2, pp.1-34, ISSN 2215-2288, julio-diciembre, 2011

proyectos". "La gestión del currículo es propia de cada docente pero el trabajo en equipo y el seguimiento garantizan el éxito". "Sí, porque permite información de primera mano a la dirección para poder hacer procesos remediales".

Quienes consideran que las funciones asignadas no garantizan el éxito en la gestión curricular afirman lo siguiente: "Las funciones asignadas solo contribuyen, sin embargo siempre se presentan situaciones ajenas al control del Coordinador Académico como exceso de matrícula, incapacidades, etc.", "Pueden mejorarlas pero no son una garantía de éxito pues son muchos los factores que intervienen", "El buen desempeño en mis funciones colabora, pero el éxito lo asegura cada docente a la hora de desarrollar el currículo nacional (contextualizado) en el aula". "Algunas veces no se cuenta con el apoyo de los docentes y también falta espacio y tiempo para llevar a cabo las actividades que se van a realzar"." En mi caso se me asignan otras que tienen que ver más con lo administrativo que con la gestión del currículo". "No, porque se han recargado mis labores en cosas administrativas".

De lo anterior se puede concluir que a pesar de que los porcentajes se dividen de igual manera entre los coordinadores consultados, aquellos coordinadores que opinan sobre las funciones asignadas sí aseguran el éxito en la gestión del currículo, expresan que existen necesidades de capacitación, falta tiempo para realizar sus tareas así como apoyo por parte de la dirección y los mismos docentes lo cual coincide con las opiniones de aquellos que optaron por la respuesta negativa. Por tanto, se recomienda a los directores hacer del conocimiento de los coordinadores académicos, las funciones del coordinador académico establecidas por el Ministerio de Educación Pública e instruirlo acerca de cómo cumplir con estas. De igual manera, se sugiere al Director no saturar al Coordinador con funciones administrativas no inherentes a su puesto, ya que estas limitan su trabajo en el área de gestión del currículo.

Desde la perspectiva del Director el porcentaje más elevado $(71,43 \%)$ correspondiente a aquellos directores los cuales consideran que "las funciones asignadas sí aseguran el éxito en la gestión curricular". La diferencia entre coordinadores y directores podría radicar en que el director tiene potestad para asignar funciones que considere pertinentes y necesarias al coordinador académico como se indica en el perfil Número publicado el 20 de diciembre de 2011 URL: http://revistadigital.eae.fcs.ucr.ac.crl 
Revista Gestión de la Educación, Vol.1, N², pp.1-34, ISSN 2215-2288, julio-diciembre, 2011

funcional donde encontramos como una función: "otras labores que el director designe", lo cual le da la autoridad para seleccionar tareas que considere importantes para el éxito de la gestión curricular.

Lo ideal sería que existiese una descripción de puesto en Servicio Civil que definiera claramente este trabajo y sus funciones y que el MEP propiciara la apropiación de este puesto por parte de los Coordinadores a través de la capacitación, pues en la medida en que tanto directores como coordinadores tengan claro el papel del coordinador dentro de la organización educativa será más fácil que se alcance el éxito en la gestión curricular.

\section{¿En qué consiste la labor de quienes ejercen el rol de coordinación académica en las organizaciones educativas de secundaria pública?}

Al consultar a los coordinadores académicos sobre en qué consiste su papel como coordinadores, las respuestas más frecuentes son:

El papel del coordinador está relacionado con el apoyo a la dirección y los docentes en todo lo concerniente a la parte académica.

"Enlace entre los estudiantes, los padres de familia y la institución", "Un enlace entre el docente y la dirección", "Servir de apoyo a las funciones de la dirección en todo lo relacionado con lo académico", "Recibir planes y darles seguimiento", "Apoyar a los docentes y dar recomendaciones a los docentes".

Se encuentran así, una gran parte de consultados los cuales consideran que su papel es servir de enlace entre el personal docente y la dirección. Los coordinadores académicos también señalan que su papel radica en un apoyo a la dirección en todo lo relacionado con la parte académica.

Los coordinadores describen su papel utilizando las funciones más frecuentemente asignadas por el director de la institución; sin embargo, no todos coinciden a la hora de definir el rol que juegan dentro de la organización educativa. Es importante recalcar aquí lo publicado por la Fundación Chile (2006) que señala la falta de claridad en las funciones Número publicado el 20 de diciembre de 2011 URL: http://revistadigital.eae.fcs.ucr.ac.crl 
Revista Gestión de la Educación, Vol.1, º2, pp.1-34, ISSN 2215-2288, julio-diciembre, 2011

y la confusión en los papeles de las personas que laboran en las organizaciones educativas como uno de los principales problemas de los sistemas educativos de Latinoamérica. De ahí la importancia en este proyecto de investigación de definir claramente el papel del coordinador y sus funciones como gestor del currículo en las organizaciones de secundaria.

Desde la perspectiva del director, el papel de la coordinación académica está ligado al éxito escolar, al rendimiento académico y al apoyo de los docentes en materia de planeamiento.

\section{¿Cuáles son las funciones esenciales del coordinador académico en la gestión del currículo?}

De acuerdo con los datos obtenidos se establecen las funciones esenciales del coordinador académico:

- Desde la perspectiva del Coordinador Académico:

1. Dar seguimiento al planeamiento didáctico de los docentes.

2. Planear y fortalecer estrategias para mejorar el rendimiento académico.

3. Asesorar a los docentes en materia de planeamiento.

4. Organizar o colaborar con la organización de actividades relacionadas con el desarrollo curricular.

5. Colaborar con el comité de evaluación, apoyo y otros.

- Desde la perspectiva del Director:

1. Recoger y revisar planeamientos.

2. Promover capacitaciones para el personal docente.

3. Realizar informes de rendimiento académico.

Número publicado el 20 de diciembre de 2011 URL: http://revistadigital.eae.fcs.ucr.ac.crl 
Revista Gestión de la Educación, Vol.1, N², pp.1-34, ISSN 2215-2288, julio-diciembre, 2011

4. Coordinar actividades en apoyo a la dirección relacionadas con el desarrollo curricular.

\section{¿Cuáles son las funciones administrativas inherentes al cargo de coordinación académica?}

Cuando se consultó a los coordinadores académicos acerca de las funciones administrativas inherentes a su cargo las respuestas más habituales fueron las siguientes:

1. Dar seguimiento al rendimiento académico a través del análisis cualitativo y cuantitativo.

2. Realizar reuniones periódicas en coordinación con la dirección.

3. Recoger y revisar planeamientos.

4. Realizar informes relacionados con la entrega de documentos.

5. Buscar y coordinar capacitaciones.

Los directores consideran como funciones administrativas inherentes al cargo del coordinador académico:

1. Recibir y revisar planes.

2. Colaborar con la conformación de horarios.

3. Llevar estadísticas de rendimiento.

4. Elaborar proyectos curriculares innovadores.

5. Participar en reuniones.

Número publicado el 20 de diciembre de 2011 URL: http://revistadigital.eae.fcs.ucr.ac.crl 
Revista Gestión de la Educación, Vol.1, N², pp.1-34, ISSN 2215-2288, julio-diciembre, 2011

\section{Nivel de cumplimiento de las funciones de coordinación académica}

Utilizando el perfil establecido en la directriz emanada por el MEP, a partir de la viceministra de educación Alejandrina Mata (2006-2010), acerca de las funciones con las que debe cumplir el coordinador académico en las organizaciones educativas de secundaria se solicitó a los participantes que marcaran si la función se realizaba en $A$ (Alto), M (Medio), B (Bajo) nivel, y que no eligieran ninguna opción si la función no se realizaba del todo.

Desde la perspectiva de los Coordinadores Académicos: al realizar la adición de los niveles alto y medio se obtiene que las funciones relacionadas con el planeamiento, la organización y el control obtienen porcentajes sobre el 50\%. Todas las funciones relacionadas con la dirección alcanzaron el 65\%.

Como resultado de este proceso de adición en los resultados obtenidos de los cuestionarios realizados a los Directores se encuentra que todas las funciones de planeamiento, organización y dirección alcanzaron el 65\%, mientras que las relacionadas con el control en su totalidad alcanzaron el $70 \%$.

\section{Conclusiones}

Una vez concluido el estudio y utilizando como punto de referencia los objetivos planteados al inicio de este, se presentan las principales conclusiones:

- Los coordinadores académicos consideran que su papel está estrictamente relacionado con el apoyo a la dirección y los docentes en todo lo concerniente a la parte académica.

- Desde la perspectiva de la dirección, el papel de la coordinación académica está asociado al éxito escolar, al rendimiento académico y al apoyo del personal docente en materia de planeamiento.

Número publicado el 20 de diciembre de 2011 URL: http://revistadigital.eae.fcs.ucr.ac.crl 
Revista Gestión de la Educación, Vol.1, N², pp.1-34, ISSN 2215-2288, julio-diciembre, 2011

- Las direcciones que fueron consultadas consideran como funciones indispensables en el área de gestión del currículo: la recolección y revisión de planeamientos, la promoción de capacitaciones para el personal docente, la realización de informes de rendimiento académico, la coordinación de actividades en apoyo a la dirección relacionadas con el desarrollo curricular.

- Desde la visión de las coordinaciones académicas consultadas, las funciones esenciales ésta en el área administrativa consisten en: recibir planeamientos, dar seguimiento al rendimiento académico a través del análisis cualitativo y cuantitativo, realizar informes, realizar reuniones periódicas en coordinación con la dirección con los coordinadores de nivel, de departamento y con los profesores, hacer informes relacionados con el cumplimiento y entrega de documentos por parte de los profesores y promover capacitaciones para el personal docente.

- Según el personal directivo consultado, las funciones de la coordinación académica en el área administrativa consisten en: recibir y revisar planes, orientar la labor docente, colaborar con la conformación de horarios, llevar estadísticas de rendimiento, elaborar proyectos curriculares innovadores, participar en reuniones.

- El personal docente que lleva a cabo la coordinación académica y el personal directivo, coinciden en que las funciones relacionadas con el planeamiento en general, se realizan en alto grado. Las funciones relacionadas con la planificación de actividades curriculares las más importantes, mientras que el nivel de cumplimiento de las funciones concernientes a la organización es alto, teniendo trascendencia las tareas que atañen al rendimiento académico y al mejoramiento curricular, así como las funciones referentes a la dirección se cumplen en un alto nivel, siendo las funciones de enlace, asesoramiento a los docentes y ayuda a la dirección las más destacadas.

- Las funciones de control, en su totalidad, superan el $50 \%$, por lo que obtienen los mejores porcentajes las funciones de recoger y revisar planeamientos, dando recomendaciones pertinentes y las relacionadas con la elaboración de informes a la dirección sobre rendimiento académico y actividades curriculares realizadas.

Número publicado el 20 de diciembre de 2011 URL: http://revistadigital.eae.fcs.ucr.ac.crl 
Revista Gestión de la Educación, Vol.1, №2, pp.1-34, ISSN 2215-2288, julio-diciembre, 2011

- Los y las profesionales consultados, se inclinan por el liderazgo de quien ocupa la dirección como el factor de mayor incidencia en la labor de coordinación académica.

- La mayoría del personal directivo (72,43\%), considera que las funciones que se asignan a quien cumple el rol en la coordinación académica, aseguran el éxito de la gestión del currículo. Por otro lado, el personal docente que lleva a cabo la coordinación académica presentan opiniones divididas al respecto.

- Las personas que cumplen el rol en la coordinación académica cuentan con el perfil funcional establecido por el Ministerio de Educación Pública. Sin embargo, pocas cuentan con un perfil propio determinado en el seno de la institución y adecuado a las necesidades de la organización educativa.

- Un alto porcentaje de quienes cumplen las funciones de coordinación académica, cuentan con los recursos básicos para realizar sus labores. Sin embargo, se pudo constatar que los mismos no son de alta accesibilidad, lo que representa una limitante para su trabajo.

- Además, no todas las personas en la coordinación académica tienen claridad en sus funciones y desconocen que existe un perfil funcional definido por el Ministerio de Educación Pública.

- Existe una imperiosa necesidad por parte de quienes ejercen la coordinación académica de contar con una descripción de puesto por parte de la Dirección de Servicio Civil, acorde con la realidad de las organizaciones educativas nacionales.

- A partir del análisis de los datos y en particular, en las manifestaciones planteadas por el personal directivo y de coordinación académica, se pueden establecer las acciones reales que conforman el perfil funcional, en relación con las áreas y el nivel de importancia. Este perfil, se detalla a continuación:

Número publicado el 20 de diciembre de 2011 URL: http://revistadigital.eae.fcs.ucr.ac.crl 
Revista Gestión de la Educación, Vol.1, N², pp.1-34, ISSN 2215-2288, julio-diciembre, 2011

\begin{tabular}{l} 
Planeamiento \\
\hline Planifica las actividades del área curricular \\
\hline $\begin{array}{l}\text { Planea actividades con el fin de difundir el Proyecto Educativo Institucional asegurando la } \\
\text { participación de la comunidad educativa y el entorno. }\end{array}$ \\
\hline Realiza un diagnostico de las necesidades de formación profesional. \\
\hline $\begin{array}{l}\text { Propicia estrategias óptimas para el desarrollo integral de los y las participantes en el proceso de } \\
\text { enseñanza y aprendizaje }\end{array}$ \\
\hline $\begin{array}{l}\text { Organización } \\
\text { estrategias y técnicas que contribuyan al mejoramiento curricular }\end{array}$ \\
\hline Coordina los programas de desarrollo curricular a nivel institucional. \\
\hline Realizar por orden de la dirección, reuniones periódicas con los Coordinadores de Nivel o Ciclo. \\
\hline Colaborar con el Comité de Apoyo, en todo lo relacionado con la adecuación curricular. \\
\hline \multicolumn{1}{c|}{ Dirección } \\
\hline $\begin{array}{l}\text { Asesora y orienta al personal docente en el cumplimiento de las directrices curriculares } \\
\text { establecidas por el MEP. }\end{array}$ \\
\hline Asesora al personal docente en la implementación y adecuación de planes y programas. \\
\hline Coadyuva en el proceso de evaluación docente con respecto al desarrollo de programas. \\
\hline Sirve de enlace entre el personal docente y la Dirección \\
\hline \multicolumn{1}{c|}{ Control } \\
\hline Recibe y revisa el planeamiento didáctico de los y las docentes y da recomendaciones pertinentes. \\
\hline Informa al director los resultados obtenidos de las actividades realizadas en el área curricular. \\
\hline $\begin{array}{l}\text { Participa en reuniones mensuales con la dirección del Centro Educativo con el fin de informar } \\
\text { sobre la marcha regular de la institución y valorar situaciones propias del quehacer institucional. }\end{array}$ \\
\hline Realiza estudios de rendimiento académico \\
\hline
\end{tabular}

\section{Referencias}

Arroyo, J. A. (2009). Gestión directiva del curriculum. Actualidades Investigativas en Educación, 9 (2), 1-17. Recuperado de http://revista.inie.ucr.ac.cr/ediciones/controlador/Article/accion/show/articulo/gestio n-directiva-del-curriculum.html

Ary, D.; Jacobs, L., Ch. y Razavieh, A. (1989). Introducción a la investigación pedagógica. México: Interamericana.

Número publicado el 20 de diciembre de 2011 URL: http://revistadigital.eae.fcs.ucr.ac.crl 
Revista Gestión de la Educación, Vol.1, N², pp.1-34, ISSN 2215-2288, julio-diciembre, 2011

Bar, G. (1999). Perfil y competencias del docente en el contexto institucional educativo. Seminario taller sobre perfil del docente y estrategias de formación. Perú: OEI. Recuperado de http://www.oei.org.co/de/gb.htm

Bravslavsky, C., Acosta, F. y Jabif, L. (2004). Orientaciones conceptuales y didácticas, Liderazgo. Módulos de formación en competencias para la gestión escolar en contextos de pobreza. Buenos Aires: IIPE-UNESCO.

Fonseca, C. M. (2006). Análisis del modelo de gestión de administrativa de la Escuela Nueva Laboratorio. Informe final para optar por el grado de Máster en Administración Educativa. Universidad de Costa Rica, San José, Costa Rica.

Fundación Chile (2006). Gestión escolar: Perfil de competencias jefe de unidad técnico pedagógica. Recuperado de http://www.gestionescolar.cl/images/stories/perfiles competencias/JefeUTP.pdf

Fundación Chile. (2006). Gestión Escolar: Manual de gestión de competencias para directivos, docentes y profesionales de apoyo en instituciones escolares. Recuperado de http://s3.amazonaws.com/lcp/ximecatalandocencia/myfiles/COMPETENCIASDOCENTES-FUND.-CHILE.pdf

González, V. y Unfried, J. (2005). Modelos de gestión educativa en la sociedad contemporánea. Ponencia II Congreso Internacional de Administradores de la Educación, Universidad de Costa Rica, San José, Costa Rica. Recuperado de www.eae.ucr.ac.cr/...\%202005/Ponencia.\%20Victoria\%20GonzalezJennifer\%20Unfried.doc

Hernández, R., Fernández, C. y Batista, P. (2010). Metodología de investigación. México: McGraw-Hill.

Lepeley, M. T. (2003). Gestión y calidad en educación: Un modelo de evaluación. México: Mc Graw-Hill.

Ministerio de Educación de Chile [MINEDUC]. (2005). De la administración escolar tradicional a la gestión educativa: Pedagogía Emocional. Santiago, Chile: Gobierno de Chile.

Número publicado el 20 de diciembre de 2011 URL: http://revistadigital.eae.fcs.ucr.ac.crl 
Revista Gestión de la Educación, Vol.1, º2, pp.1-34, ISSN 2215-2288, julio-diciembre, 2011

Ministerio de Educación de Chile [MINEDUC]. (2009). Modelo de Gestión Escolar. Santiago, Chile. Recuperado de http://www.gestionescolar.cl/gestion-decalidad/modelo-de-gestion-escolar.html

Ministerio de Educación de El Salvador [MINED]. (2008).Gestión Escolar Efectiva. Recuperado de www.oei.es/pdf2/gestion escolar efectiva elsalvador.pdf

Ministerio de Educación Nacional de la República de Colombia [MEN]. (2009). Guía para el mejoramiento Institucional: de la autoevaluación al plan de mejoramiento. Recuperado de http://www.mineducacion.gov.co/1621/articles-177745 archivo pdf.pdf

Ministerio de Educación Pública [MEP]. (2008). Naturaleza del trabajo de coordinación académica. San José, Costa Rica: Autor.

Moorman, H., Nusche, D., Pont, B. (2009). Política y práctica. Mejorar el liderazgo escolar. Volumen I. Organización para la cooperación y el desarrollo económicos (OCDE). Recuperado en http://www.oecd.org/dataoecd/32/54/44374937.pdf

Mora, A. (2010). La gestión curricular y su implicancia en los procesos educativos de calidad. Revista Vinculando, marzo 2003. Recuperado de http://vinculando.org/educacion/la gestion curricular en procesos educativos de calidad.html

Ogando, F. A. (2004). Estado de la investigación en gestión escolar, práctica pedagógica y calidad educativa. Recuperado de http://www.ciedhumano.org/FERNANDOOGANDOInformedelnvestigacion. pdf

UNICEF. (2004) ¿Quién dijo que no se puede? Escuelas efectivas en sectores de pobreza. Recuperado de http://www.unicef.cl/centrodoc/escuelas efectivas/escuela\%20efectivas.pdf

Villareal R., E. (2005). La efectividad de la gestión escolar depende de la efectividad del recurso humano como factor, actor y promotor del cambio dentro de los procesos, dimensiones y políticas educativas. Revista Iberoamericana de Educación, 37 (2). Recuperado de http://www.rieoei.org/deloslectores/1083Villarreal.pdf

Número publicado el 20 de diciembre de 2011 URL: http://revistadigital.eae.fcs.ucr.ac.crl 